\title{
Consolidation Properties of NAPL Contaminated Sediments
}

\author{
M. B. Erten $^{1}$, C. S. El Mohtar ${ }^{2}$, D. D. Reible ${ }^{3}$, R. B. Gilbert ${ }^{4}$ \\ ${ }^{1}$ Graduate Research Assistant, University of Texas at Austin, 1 University Station \\ C1792, Austin, TX 78712-0273 (corresponding author) e-mail: \\ mberten@mail.utexas.edu \\ ${ }^{2}$ Assistant Professor, Dept. of Civil, Architectural, and Environmental Engineering, \\ Univ. of Texas at Austin, Austin, TX 78712-0273 \\ ${ }^{3}$ Bettie Margaret Smith Chair of Environmental Health Engineering, Dept. of Civil, \\ Architectural, and Environmental Engineering, Univ. of Texas at Austin, TX 78712- \\ 0273 \\ ${ }^{4}$ Brunswick-Abernathy Regents Professor in Soil Dynamics and Geotechnical \\ Engineering, University of Texas at Austin, 1 University StationC1792, Austin, TX \\ 78712-0273
}

\section{ABSTRACT}

In situ capping of contaminated sediments in rivers, lakes and ponds has been successfully used to contain the contaminants in sediments and prevent water contamination. While capping is a good alternative for remediation, the cap load may cause consolidation-induced migration of Non-Aqueous Phase Liquids (NAPLs). In this study, the consolidation properties of NAPL-contaminated sediments were investigated. Anisotropic consolidation tests were conducted on very soft contaminated sediment specimens in a modified triaxial cell. Kaolinite was used to represent the sediment solid phase and Soltrol 130 (a type of mineral oil) was used to represent the NAPL. Compression index $\left(\mathrm{C}_{\mathrm{c}}\right)$ and coefficient of consolidation $\left(\mathrm{C}_{\mathrm{v}}\right)$ values were obtained for specimens at various NAPL saturations. The hydraulic conductivity values were back-calculated by using the $\mathrm{C}_{\mathrm{v}}$ values. The results indicate that NAPL can be expelled during consolidation if its saturation is high enough. While there is not a significant change in the $\mathrm{C}_{c}$ values for different NAPL contents, $\mathrm{C}_{\mathrm{v}}$ values increase significantly when the NAPL saturation increases. When designing a cap system for contaminated sediments, the effect of NAPL on consolidation behavior is an important consideration.

\section{INTRODUCTION}

Remediation of soft sediments contaminated with Non-Aqueous Phase Liquids (NAPLs) requires special care since they usually exist at very high void ratios. In situ capping is an effective technique of sediment remediation; however, the cap load on the sediment can trigger NAPL migration into the overlying water. Knowing the volume and rate of NAPL expulsion is important while designing an in situ cap. It is proposed herein to employ consolidation testing to evaluate the potential NAPL displacement.

The very soft nature of fine grained sediments makes consolidation testing challenging. The sediments usually exist at very high void ratios in their natural state 
and may not stand under their own weight. That makes it harder to prepare and test a specimen. In addition, any expressed contaminant may need special care and should be collected separately for further analysis.

Erten et al (2011) developed a specimen preparation procedure and consolidation testing set-up by modifying a triaxial frame. Reconstituted specimens were used in the tests. The testing procedure was applied successfully on NAPL contaminated sediments. Steward (2007) and Moretti (2008) used similar testing systems to evaluate the consolidation potential of NAPL contaminated field sediments.

Thornley (2006) performed consolidation tests on kaolinite contaminated with oil. The sediment slurries were placed in a modified Rowe cell. Thornley (2006) found that oil contamination did not have a major effect on the compression of kaolinite. Ma et al. (2010) performed column tests on NAPL contaminated sediments; for those tests, specimen cores collected in the field were tested directly. Actual cap material was placed directly on the specimen in the tube to apply the consolidation load. Column tests made specimen set-up very easy and fast; however since the height to diameter ratio of samples were very high, wall friction could distort the consolidation properties.

Olson and Mesri (1970) performed consolidation tests on kaolinite with different types of pore fluid. Different pore fluids resulted in different compressibility of kaolinite. Mesri and Olson (1971) back-calculated hydraulic conductivity of kaolinite with various pore fluids from the coefficient of consolidation $\left(\mathrm{C}_{\mathrm{v}}\right)$ values using Terzaghi's consolidation theory. The hydraulic conductivity of kaolinite was higher when the pore fluid was non-polar instead of water.

In this study, a modified triaxial set-up was used for consolidation testing of NAPL-contaminated sediments. The advantages of a triaxial set-up are that; separate application of vertical and horizontal stresses help achieve $\mathrm{K}_{0}$ stress condition; the pore pressures in sediment's natural state can be applied through a separate line; and the side frictions can be eliminated by using soft and thin membranes. Consolidation tests were performed on five specimens at various initial NAPL saturations. NAPL saturation $\left(\mathrm{S}_{\mathrm{NAPL}}\right)$ is defined as the ratio of the volume of NAPL to the volume of voids. Hydraulic conductivity values were back calculated from the coefficient of consolidation $\left(\mathrm{C}_{\mathrm{v}}\right)$ values for each consolidation stage.

\section{MATERIALS}

Pure Georgia kaolinite was used to represent the soil solid phase in the sediment specimens. Kaolinite has been used in Geotechnical testing for a long time for various tests. Therefore the basic properties of kaolinite are very well defined in the literature. The liquid limit (LL) and plasticity index (PI) of kaolinite were measured as 56\% and 23\% respectively. Soltrol 130 Isoparaffin solvent was used to represent the NAPL phase in samples. Soltrol is a low viscosity $\left(1.55 \mathrm{cSt}\right.$ at $\left.38{ }^{\circ} \mathrm{C}\right)$ mineral oil and similar to a middle distillate such as kerosene or diesel. Since Soltrol is transparent, it was dyed to red to distinguish it from water. Tap water was used to represent the water phase 


\section{PROCEDURE}

The test procedure entails running anisotropic consolidation tests on specimens in a trixial cell. The following modifications were made to a conventional triaxial set-up to adapt it for consolidation testing of soft NAPL contaminated sediments. An air piston was attached at the top of the triaxial frame for accurate constant load application. Bladder accumulators were attached to the triaxial cell to collect the expelled NAPL and prevent the pressure panel being contaminated by the NAPL in the specimen. A differential pressure transducer was attached at the bottom of the cell and the specimen for accurate effective stress measurement. Pressure regulators were selected such that they can apply low stresses accurately. The test apparatus is shown in Figure 1. More details of the experimental setup can be found in Erten et al. (2011).

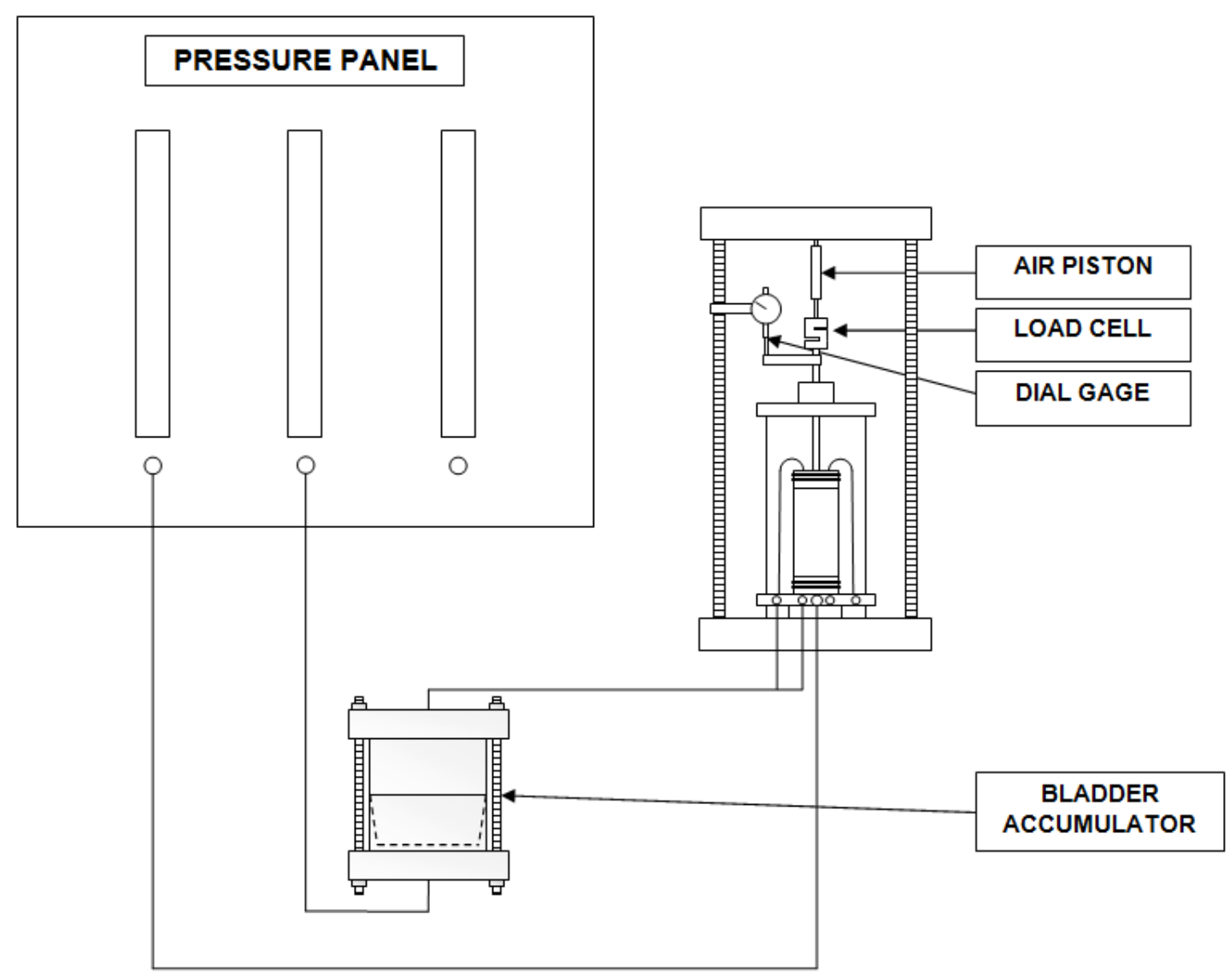

Figure 1 Schematic of Test System (Erten et al. 2011)

All specimens were mixed by hand in a bowl. Consolidation stresses were calculated for a hypothetical case in which the specimen was located $1.1 \mathrm{~m}$ below the mudline and there was $3.0 \mathrm{~m}$ of water overlying the sediment layer (Figure 2). El Sherbiny (2006) consolidated kaolinite in a tub and obtained the moisture content profile of kaolinite along the depth. By using the moisture content data obtained from 
El Sherbiny (2006), for the hypothetical case's stress condition, the initial void ratio of kaolinite was determined as 2.05 .

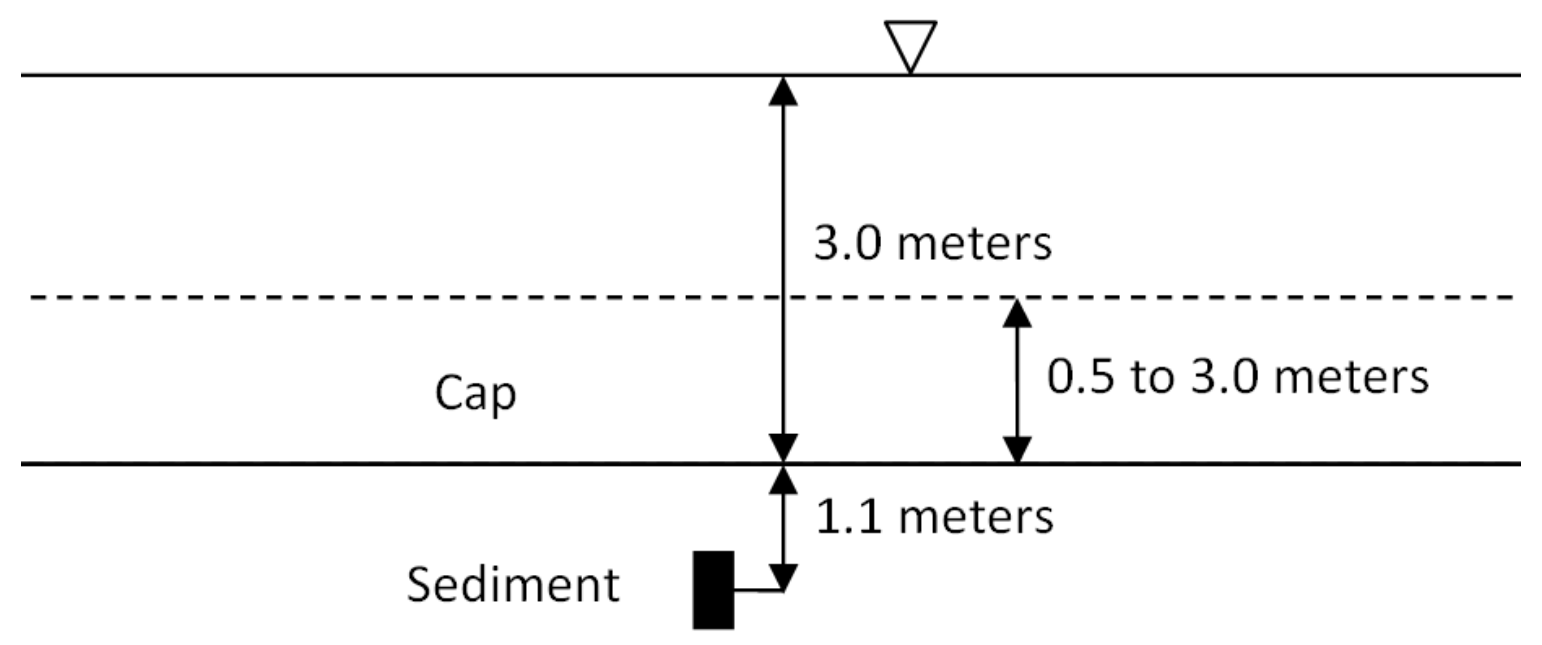

Figure 2 Hypothetical Sample Location

The sediment mixture was placed in the membrane on the triaxial base pedestal. For these tests, neoprene membranes were used since they are chemically inert. The mixture was placed into the membrane in several lifts. After each lift the mixture was tapped slightly with a metal rod for compaction. The tests were conducted under double drainage conditions. Therefore, porous stones and filter papers were placed at the top and the bottom of the specimen. The membrane was sealed to the top cap and the base pedestal with 3 o-rings at the top and the bottom.

Initial specimen preparation trials showed that when the soil was mixed to a void ratio of 2.05 , the maximum water saturation that could be achieved was $30 \%$. When more water was added into the specimen, water pushed out the NAPL and NAPL floated out of the sediment. Therefore, when higher water saturation was needed, first, a specimen was mixed at a water saturation of $30 \%$. Then, after placing the specimen into the membrane, a hydraulic head was created between the top and the bottom of the specimen and water was pushed into the specimen from the top. This caused the NAPL to come out from the bottom. This process continued until the desired NAPL saturation was achieved. For this soil at these conditions, the lateral earth pressure coefficient $\left(\mathrm{K}_{0}\right)$ was determined as in between 0.6 and 0.7 . In all tests, while calculating the horizontal effective stresses, a $\mathrm{K}_{0}$ of 0.7 was used. More details of specimen preparation procedures can be found in Erten et al. (2011).

Table 1 shows what each consolidation stage simulated in the field and corresponding vertical effective stress. The first consolidation stage simulated the in situ conditions of the soil where no cap was placed. After the first consolidation stage, B-value was checked. In all tests B-value varied between 0.95 and 0.98 which was considered satisfactory. The following consolidation stages represented varying cap heights of $0.5 \mathrm{~m}, 0.9 \mathrm{~m}, 1.8 \mathrm{~m}$, and $3.0 \mathrm{~m}$. 
Table 1 Consolidation Stages

Consolidation Stage Field Condition Vertical Effective Stress (kPa)

$\begin{array}{ccc}\text { I } & \text { In Situ } & 6.3 \\ \text { II } & 0.5 \text { m Cap } & 11.2 \\ \text { III } & 0.9 \text { m Cap } & 16.0 \\ \text { IV } & 1.8 \text { m Cap } & 25.7 \\ \text { V } & 3.0 \text { m Cap } & 38.7\end{array}$

\section{RESULTS}

Five consolidation tests were performed on specimens at various initial NAPL saturations $\left(\mathrm{S}_{\mathrm{NAPL}}\right)$. Saturation and compression index $\left(\mathrm{C}_{\mathrm{c}}\right)$ values of all samples are given in Table 2. Kaolinite was mixed with water first and then NAPL was added (except for the specimen at the initial NAPL saturation of 100\%). Compression index values do not show much variation with NAPL saturation (Table 2). However, the volume of NAPL expelled is sensitive to the initial saturation of NAPL in the sediment (Table 3).

Table 2 Compression Index $\left(\mathrm{C}_{c}\right)$ values of specimens.

\begin{tabular}{ccc} 
Test Number & Initial NAPL Saturation $\left(\mathbf{S}_{\mathbf{N A P L}}\right)$ & Compression Index $\left(\mathbf{C}_{\mathbf{c}}\right)$ \\
\hline $\mathbf{1}$ & $15 \%$ & 0.35 \\
$\mathbf{2}$ & $23 \%$ & 0.36 \\
$\mathbf{3}$ & $33 \%$ & 0.44 \\
$\mathbf{4}$ & $70 \%$ & 0.44 \\
$\mathbf{5}$ & $100 \%$ & 0.41
\end{tabular}

Table 3 Amount of NAPL displaced from $1 \mathrm{~m}^{3}$ of sediment volume

\begin{tabular}{|c|c|c|}
\hline Test Number & Initial NAPL Saturation ( $\left.\mathrm{S}_{\mathrm{NAPL}}\right)$ & $\begin{array}{l}\text { NAPL Displaced from } \\
1 \mathrm{~m}^{3} \text { of sediment (liter) }\end{array}$ \\
\hline 1 & $15 \%$ & 26.7 \\
\hline 2 & $23 \%$ & 101.1 \\
\hline 3 & $33 \%$ & 46.4 \\
\hline
\end{tabular}

Figure 3 shows the change in void ratio with increasing vertical effective stress. All specimens were mixed at the same initial void ratio of 2.05. Two specimens with initial $\mathrm{S}_{\mathrm{NAPL}}$ of $100 \%$ and $70 \%$ swelled during the first consolidation stage, which mimicked the equilibrium state of the sediment; when the NAPL content gets higher, at the same initial stresses, the equilibrium void ratio of the soil is higher because it is stiffer. It should be noted that one-dimensional strain is inversely proportional to $(1+$ initial void ratio). Therefore, if the initial void ratio after the in situ load application is higher but the change in void ratio is the same for the same change in log of effective stress ( $C_{c}$ is the same), then the strain induced by the change in effective stress is smaller and the sediment is stiffer. 
In all loading stages, either water or NAPL was expelled. On the consolidation curves in Figure 3, continuous lines denote when the expelled fluid was NAPL and dashed lines denote when the expelled fluid was water during the consolidation stage. Erten et al (2011) showed that for this soil, the NAPL was no longer mobilized with increasing compression when $\mathrm{S}_{\mathrm{NAPL}}$ was around $18 \%$,

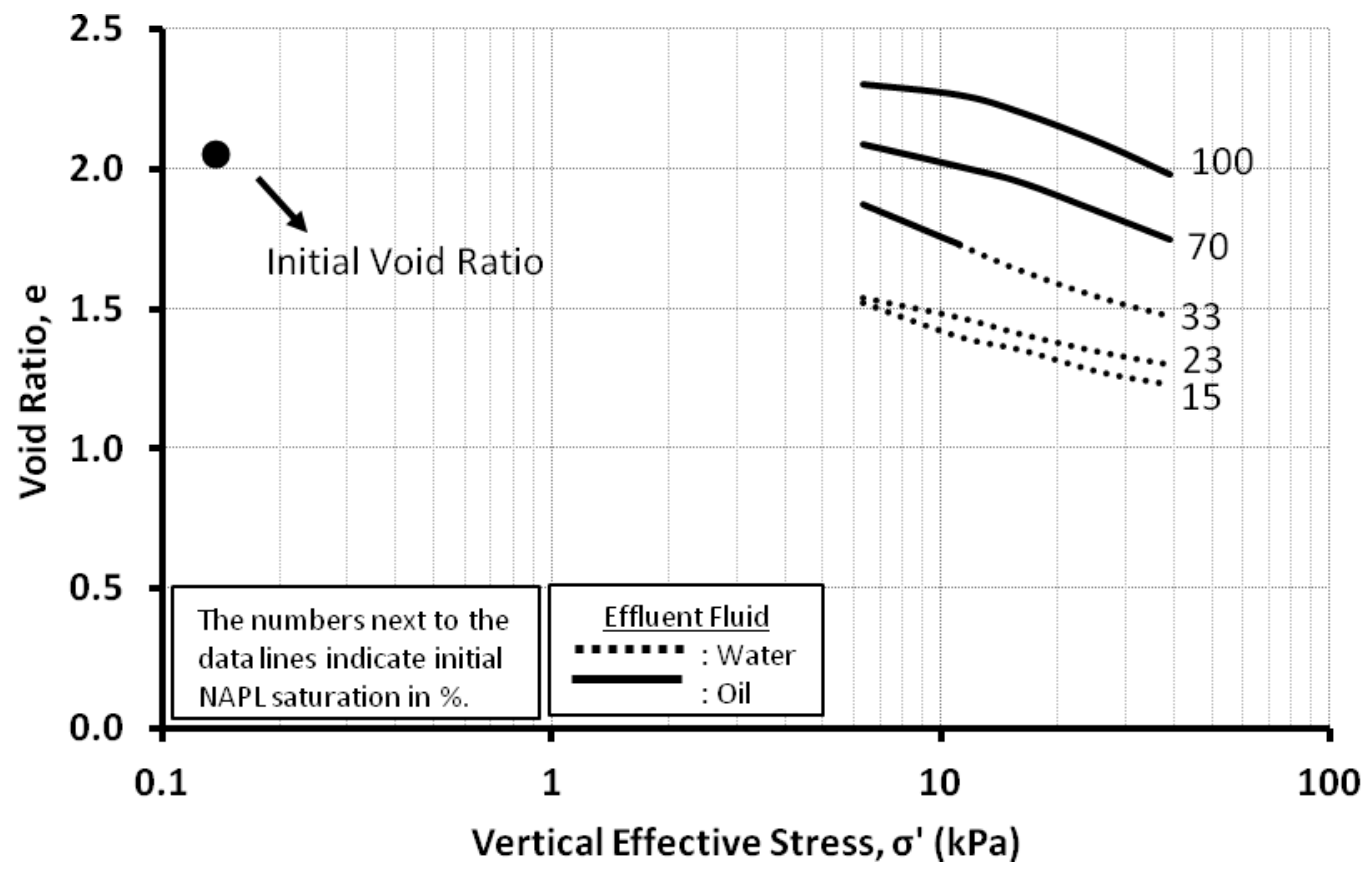

Figure 3 Void Ratio (e) vs. Vertical Effective Stress Relation of All Samples

Figure 4 shows the coefficient of consolidation $\left(\mathrm{C}_{\mathrm{v}}\right)$ values at each consolidation stage. The $\mathrm{C}_{\mathrm{v}}$ values were calculated from the best-fitted theoretical consolidation curve on the consolidation data. For each consolidation test, solid data points indicated that the expelling fluid was NAPL and hollow data points show that during that consolidation stage only water was expelled. When the expelling fluid was NAPL, there was a significant increase in the $\mathrm{C}_{\mathrm{v}}$ value due to a relatively high hydraulic conductivity for NAPL. The difference in the $\mathrm{C}_{\mathrm{v}}$ value approached two orders of magnitude depending on whether water or NAPL was being expelled.

Figure 5 shows the change in hydraulic conductivity of expelling fluid with increasing vertical effective stress. Hydraulic conductivity values were backcalculated from $\mathrm{C}_{\mathrm{v}}$ values by using Terzaghi's one dimensional consolidation theory. The hydraulic conductivity for NAPL increased as the initial saturation of NAPL increased. There was almost three orders of magnitude increase in hydraulic conductivity when NAPL versus water was expelled from the specimen.

The results indicate that NAPL and water contents at each consolidation stage have an effect on both the $\mathrm{C}_{\mathrm{v}}$ and hydraulic conductivity values. When clay particles are exposed to non-polar fluids, such as Soltrol 130 in this study, the diffused double layers around the clay particles will shrink (Lambe and Whitman 1969). Therefore, when the initial void ratios are similar, the soil will tend to form a more flocculated structure and the hydraulic conductivity and $\mathrm{C}_{\mathrm{v}}$ values will increase with an increase 
in the NAPL content, Further investigation is needed to study the effect of the NAPL and water contents, at or during each loading stage, on the consolidation properties

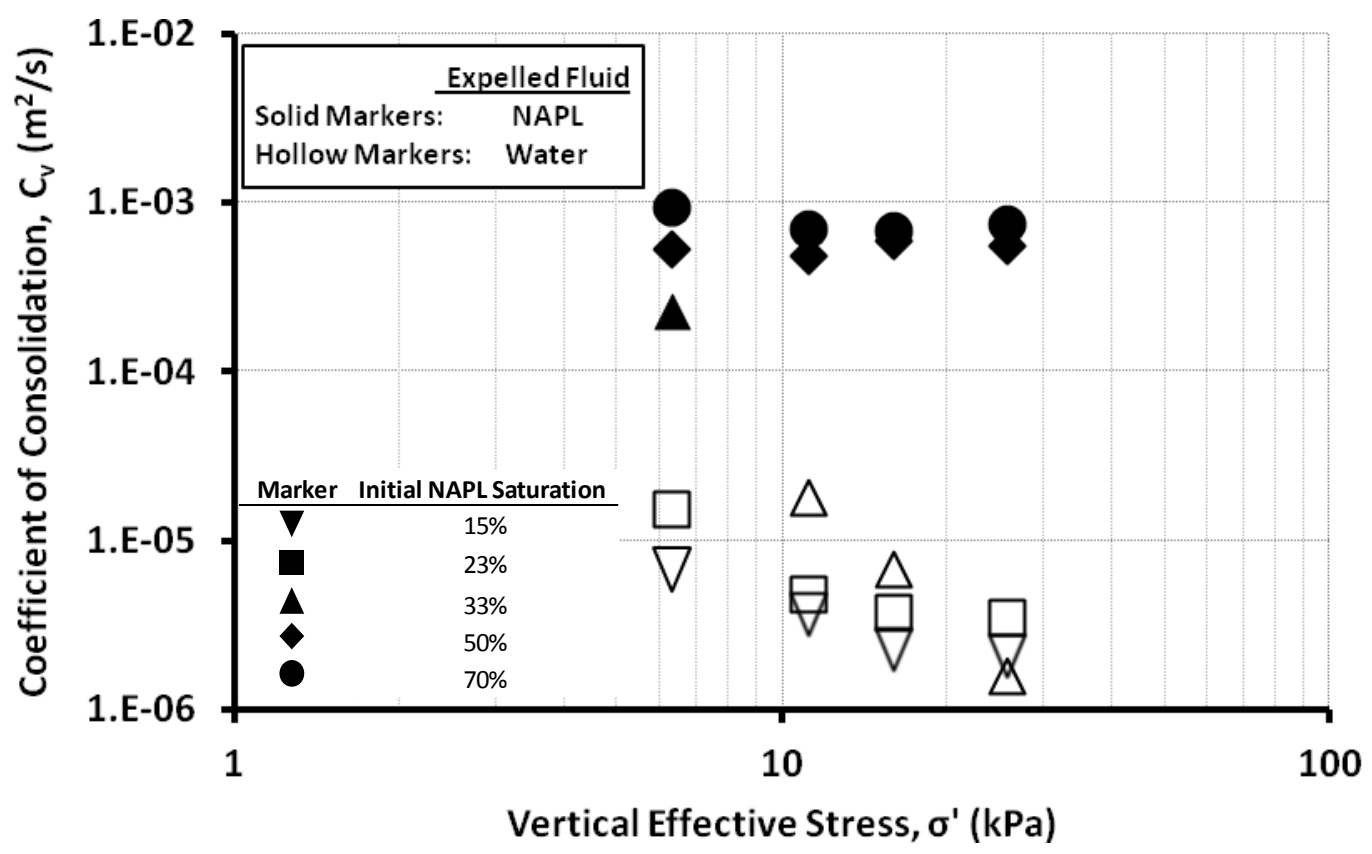

Figure 4 Coefficient of Consolidation $\left(\mathrm{C}_{\mathrm{v}}\right)$ Values at each Consolidation Stage

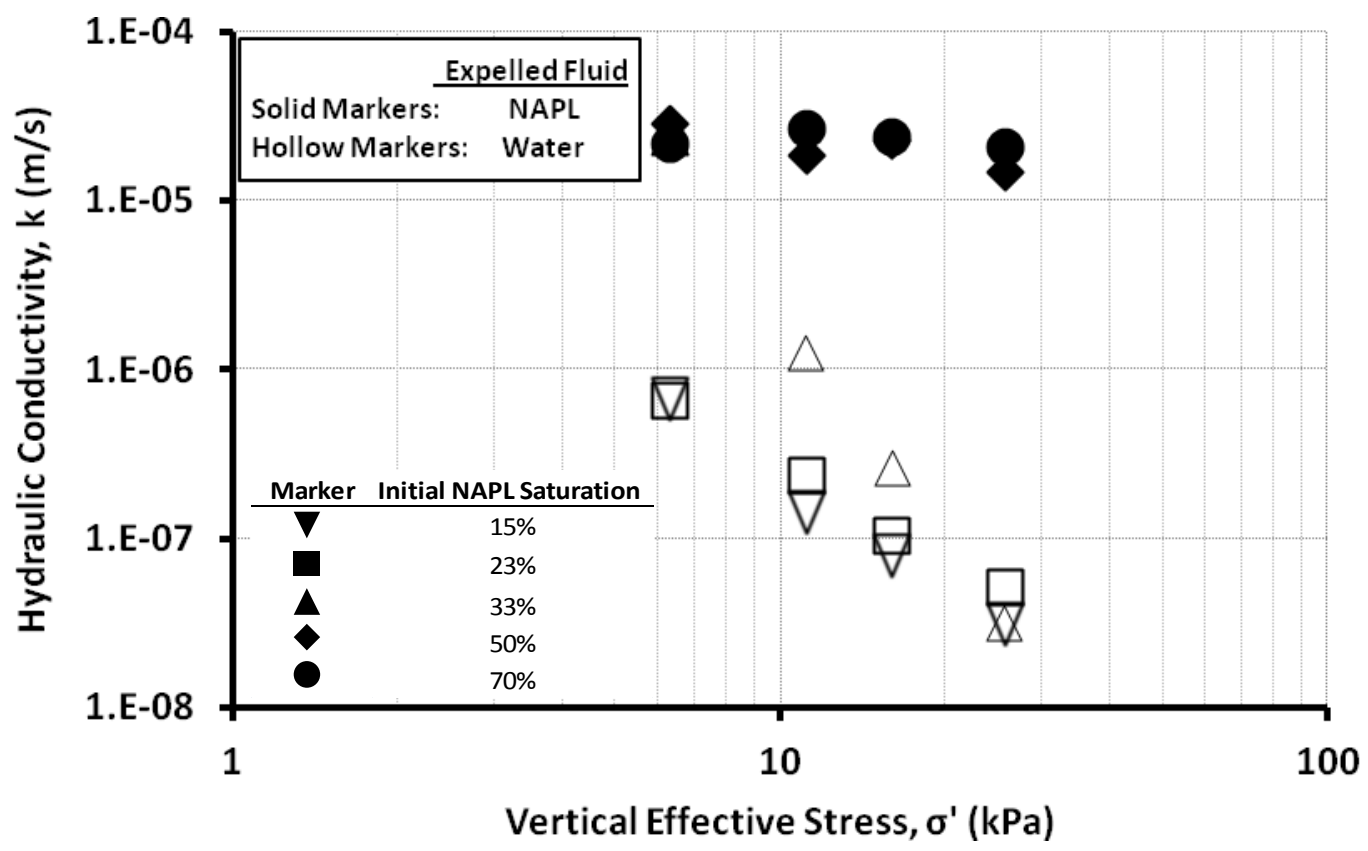

Figure 5 Hydraulic Conductivity (k) Values at each Consolidation Stage 


\section{CONCLUSIONS}

Consolidation testing on NAPL contaminated sediments are specifically challenging due to their very soft nature and presence of contaminants in them that may need special care. In addition, especially while testing surficial sediments, the testing system should be suitable to accurately apply very low stresses as in the field conditions. In this study a conventional triaxial frame was modified to adapt for these specific needs. Kaolinite, Soltrol 130 and tap water were used to simulate the sediment solids, NAPL and water phases in the real NAPL contaminated sediments, respectively.

Five consolidation tests were performed on NAPL contaminated sediment which had varying NAPL saturation in the range of $15 \%$ to $100 \%$. The total and effective stresses represented placement of a 0.5 to $3.0-\mathrm{m}$ thick cap placed on a $1.1-\mathrm{m}$ thick, submerged sediment. For this soil, the results showed that;

- Consolidation coefficient $\left(C_{c}\right)$ values were effectively independent of NAPL saturation. $C_{c}$ values were in the range between 0.36 and 0.44 . However, the equilibrium void ratio increased with increasing NAPL saturation, meaning that the stiffness of the sediment increased with increasing NAPL saturation.

- In each consolidation stage either only NAPL or water was expelled from the specimen. The $\mathrm{C}_{\mathrm{v}}$ and hydraulic conductivity values depended on the expelled fluid. When NAPL versus water was expelled, $\mathrm{C}_{\mathrm{v}}$ was one to two orders of magnitude greater and the hydraulic conductivity was as much as three orders of magnitude greater. This increase in stiffness and hydraulic conductivity is attributed to the fact that the clay minerals in the sediment formed a more flocculated structure when exposed to the nonpolar NAPL.

- A slight increase in $\mathrm{C}_{\mathrm{v}}$ and hydraulic conductivity was observed with increasing initial NAPL saturation, when the same type of fluid expelled at the same vertical effective stress.

- For design, the consolidation properties of the sediment may change drastically depending on the NAPL type and NAPL saturation. An extensive consolidation testing program may be required to evaluate NAPL release characteristic under load.

\section{REFERENCES}

El-Sherbiny, R. M. 2006. Performance of suction caisson anchors in normally consolidated clay. In Civil, Architectural, and Environmental Engineering. The University of Texas at Austin.

Erten, M. B., R. B. Gilbert, C. S. El Mohtar \& D. D. Reible (2011) Development of a laboratory procedure to evaluate the consolidation potential of soft contaminated sediments. Geotechnical Testing Journal, 34.

Lambe, T. W. \& R. V. Whitman. 1969. Soil mechanics. John Wiley \& Sons Inc. 
Ma, X., D. D. Reible \& M. Harris (2010) Assessment feasibility of in-situ capping and contaminant mobility in NAPL-contaminated sediments. International Journal of Geotechnical Engineering, 4, 71-78.

Mesri, G. \& R. Olson (1971) Mechanisms controlling the permeability of clays. Clays and Clay Minerals, 19, 151-158.

Moretti, L. K. 2008. Evaluation of Capping NAPL-contaminated Sediment. 95. Austin TX: The University of Texas at Austin.

Olson, R. E. \& G. Mesri (1970) Mechanisms controlling compressibility of clays. Journal of the Soil Mechanics and Foundations Division, 96, 1863-1878.

Steward, K. K. 2007. Development of Apparatus and Method for Consolidating Very Soft, Contaminated Sediment. Austin TX: The University of Texas at Austin.

Thornley, D. M., W. B. Wilkinson \& A. Parker (2006) A preliminary investigation of the release of oil from contaminated clays and other fine-grained sediments during consolidation. Quarterly Journal of Engineering Geology \& Hydrogeology, 39, 375-390. 